\title{
A prospective health impact assessment of the international astronomy and space exploration centre
}

\author{
L Y Winters
}

\begin{abstract}
Study objectives-Assess the potential health impacts of the proposed International Astronomy and Space Exploration Centre on the population of New Wallasey. Contribute to the piloting of health impact assessment methods.

Design-Prospective health impact assessment involving brainstorming sessions and individual interviews with key informants and a literature review. Setting-New Wallasey Single Regeneration Budget 4 area.

Participants-Key stakeholders including local residents' groups selected through purposeful snowball sampling.

Main results-Recommendations are made that cover issues around: transport and traffic; civic design; security; public safety, employment and training.

Conclusions-Health impact assessment is a useful pragmatic tool for facilitating wide consultation. In particular engaging the local population in the early planning stages of a proposed development, and assisting in highlighting changes to maximise the positive health influences on affected communities.

(F Epidemiol Community Health 2001;55:433-441)
\end{abstract}

Health impact assessment can be defined as "the estimation of the effects of a specified action on the health of a defined population.". Health should ideally be viewed holistically as not just the absence of disease, but a "complete state of physical mental and social well-being." More recently health has been described as "the optimum physical and mental functioning that a person is capable of achieving." ${ }^{3}$ It is now generally understood that health can be influenced by more than just the provision of health care. The determinants of health are very wide encompassing biological, psychological, economic, sociological and environmental issues. Furthermore, there is growing consensus and documented evidence ${ }^{45}$ that specific actions that grow out of public policy, can affect these determinants so they influence health either positively or negatively. Where geographical areas suffer relative deprivation of these important determinants, health indicators consistently show relatively poorer health of residents when compared with those living in more prosperous regions and this health divide is growing. ${ }^{6} 7$

Acheson recommends that: "all policies likely to have a direct or indirect effect on health should be evaluated in terms of their impact on health inequalities, and should be formulated in such a way that by favouring the less well off they will, wherever possible, reduce such inequalities." "Therefore recent UK government documents support health impact assessment emphasising the public health function of health authorities to evaluate "the health impact of local plans and developments." ${ }^{8}$ Furthermore, the government has pledged to apply health impact assessments to its own relevant key policies, so health consequences can be considered during their development and implementation. ${ }^{9}$ It is therefore timely that health impact assessments be undertaken prospectively, ideally at the planning stage of policies, developments and projects.

This study is one of four, enabling the Liverpool Public Health Observatory to pilot its methods for health impact assessment. ${ }^{10-13}$ The assessment focused on the three components of the proposed International Astronomy and Space Exploration Centre: Telescope Technologies Limited, Astrophysics Research Institute and the Visitor's Centre. This development is incorporated in a revitalisation programme of the Dock Estate featured in the New Wallasey regeneration strategy supported by the Single Regeneration Budget 4 . New Wallasey incorporates seven of the most deprived area on the Wirral peninsula, Merseyside, in the north west of England. The Single Regeneration Budget 4 is the fourth round of bids for a UK government funded programme providing support from a single budget for sustainable regeneration, economic development and industrial competitiveness.

Telescope Technologies is a joint initiative by Liverpool John Moores University and the Royal Greenwich Observatory to manufacture research standard astronomical telescopes. The Astrophysics Research Institute would be primarily concerned with furthering astronomical research and developing an internationally recognised centre of excellence. John Moores University staff would contribute to wider educational and public understanding of science work, cooperating daily with the Visitor Centre. The Research Institute would also be the command centre for the robotically operated Liverpool Telescope sited in the Canary Islands. Visitors to the centre will have an opportunity to learn about the latest results from programmes investigating the universe and be helped to understand the technologies that go into the development and construction 
Table 1 Key stakeholders

Key stakeholders constitute the following groups invited to participate in the HIA

- Local residents effected by the development.
People who may use the site such as local primary and secondary schools and colleges in the area.

- Those involved with the development of the docklands' site and the New Wallasey area. This included relevant voluntary organisations and professionals such as planners, environmental health officers, public health professionals, members of the special initiative team, public transport officials and community representatives

of the world's most sophisticated optical instruments, while observing their assembly. It aims to communicate aspects of modern astronomy and space science, current research by the astrophysics group at John Moores University and picture data from the Liverpool Telescope.

Approximately 30 direct jobs on site and 30 indirect jobs will be created or safeguarded in the region. Each year approximately 150 teachers would attend training courses, 12200 pupils would attend specialised activities and between 100000 to 200000 members of the general public would visit. Annual expenditure for the Research Institute and the Visitor Centre is estimated to be $£ 150000$ for running costs with fit-out and capital costs of $£ 890$ 000. The total cost over the first five years would be approximately $£ 5.94$ million. Telescope Technologies total set up and running costs would be in the region of $£ 2$ million.

\section{Procedures}

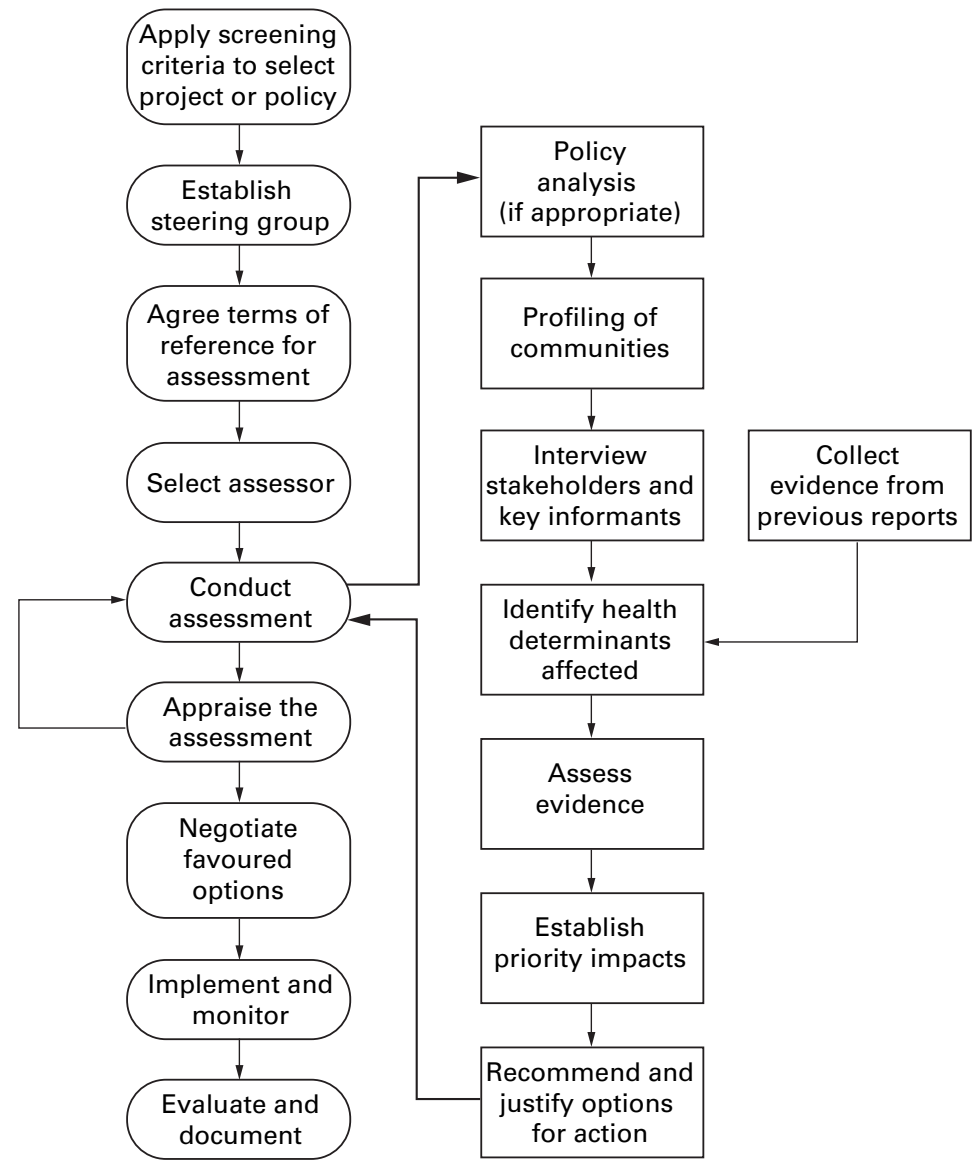

Methods

Figure 1 Stages in the health impact assessment process. Source: Merseyside Guidelines for Health Impact Assessment.

\section{Methods}

To facilitate the research process and agree on terms of reference of the health impact assessment a New Wallasey health impact assessment group was formed. Membership included community representation, assistant director of environmental health, public health and planning professionals and the project manager from the Astrophysics Department, John Moores University.

Detailed guidelines for carrying out a health impact assessment have been discussed in some detail elsewhere ${ }^{12}{ }^{14}$ and are outlined in figure 1 taken from the Merseyside Guidelines. ${ }^{14}$ The methods described in the Merseyside Guidelines incorporate tested elements of various approaches to health impact assessment, such as those previously used in the Canadian province of British Columbia ${ }^{15}$ and in Australia ${ }^{16}$.

The main stages of the health impact assessment to be reviewed in this paper are:

- Application of the screening criteria for selection of policies/projects for health impact assessment

- Profiling of potentially affected areas and communities

- Collection of qualitative data from key informants

- Literature review

- Selection of highest priority impact areas

- Recommendations for management of priority impacts

On applying the Observatory's health impact assessment screening criteria $^{14}$ this development was chosen because it could be assessed prospectively in the planning stage of its development. It was of sufficient size and cost; had relevance to local decision making with a high frequency of potential impacts. In addition, it was not politically contentious, so its acceptability to local businesses and communities would make it suitable to the development of methods of health impact assessment.

Profiling of affected communities took place by firstly reading available literature ${ }^{17-21}$ as well as interviewing key informants from planning and public health during November and December 1997. Members of the New Wallasey Partnership Board and the Docklands Steering Group were invited to participate. Members of the New Wallasey health impact assessment also contributed and put forward further participants that were contacted directly by the researcher. These informants were chosen because they had knowledge of the area through residence, professional/voluntary role or because of their expertise in issues concerning the development. Other key informants were identified from asking interviewees for further contacts. Indeed, the key informants are synonymous with key stakeholders (table 1), unless they were contacted specifically for their expertise on a particular issue. An anonymised list of participants is given in table 2. All potential informants were contacted by letter and asked if they wished to participate and given a brief résumé on the proposed development, with an explanation of what would be expected of them. During January 
Table 2 Key informants

\begin{tabular}{|c|c|c|}
\hline Date & Participating organisation & $\begin{array}{l}\text { Numbers from } \\
\text { organisation }\end{array}$ \\
\hline \multicolumn{3}{|l|}{ Briefing } \\
\hline $21 / 11 / 97$ & Special Initiatives Team & 1 \\
\hline $4 / 12 / 97$ & Public Health Facilitator & 1 \\
\hline \multicolumn{3}{|c|}{ Interview/brainstorming sessions } \\
\hline $15 / 1 / 98$ & St. Lawrence RC Primary & 2 \\
\hline $23 / 1 / 98$ & SATRO, Teachers Resource Centre, Bromborough & 1 \\
\hline $26 / 1 / 98$ & Under 5s Centre, St. Paul's Road & 9 \\
\hline $26 / 1 / 98$ & Poulton Primary & 1 \\
\hline 29/1/98 & Young parents group, Leasowe Women's Centre & 10 \\
\hline $2 / 2 / 98$ & Pleasington High, Bebington & 1 \\
\hline \multirow[t]{13}{*}{$3 / 2 / 98$} & Peter Jost Enterprise Centre & 1 \\
\hline & Public Health Locality Facilitator & 2 \\
\hline & Seacombe Neighbourhood Resource Centre & 1 \\
\hline & Councillor, MBW & 1 \\
\hline & Local Residents & 2 \\
\hline & Planning and EC Dev. Department & 1 \\
\hline & Environmental Health & 1 \\
\hline & Public Health Medicine & 1 \\
\hline & Seacombe/Poulton SRB & 1 \\
\hline & Special Initiatives Team & 1 \\
\hline & Groundwork Trust & 1 \\
\hline & Merseytravel & 1 \\
\hline & New Wallasey Board & 2 \\
\hline $9 / 2 / 98$ & Public Health Medicine & 1 \\
\hline $10 / 2 / 98$ & Weatherhead School & 1 \\
\hline $10 / 2 / 98$ & $\begin{array}{l}\text { South Wallasey Neighbourhood college (Students and member } \\
\text { of teaching staff) }\end{array}$ & 7 \\
\hline $9 / 2 / 98$ & Public Health Professional & 1 \\
\hline $6 / 2 / 98$ & YMCA, Wallasey & 1 \\
\hline $11 / 2 / 98$ & Hamilton Quarter Project Officers & 2 \\
\hline $13 / 2 / 98$ & CVS Birkenhead & 1 \\
\hline
\end{tabular}

Table 3 Key areas influencing health Biological factors
Personal / family circumstances and
$\quad$ lifestyle

Social environment

Physical environment

Public services

Public policy age, sex, genetic factors

family structure and functioning, primary secondary / adult education, occupation, income, risk taking behaviour, diet, smoking, alcohol, substance misuse, exercise, recreation, means of transport (cycle / car ownership)

culture, peer pressures, discrimination, social support neighbourliness, social networks / isolation), community / cultural / spiritual participation

air, water, housing conditions, working conditions, noise, smell, view, public safety, civic design, shops (location / range / quality), communications (road rail), land use, waste disposal, energy, local environmental features

access to (location / disabled access) and quality of primary / community / secondary health care, child care, social services, housing / leisure / employment social security services, public transport, policing, other health relevant public services, non-statutory agencies and services

economic / social / environmental / health trends, local and national priorities, policies, programmes, projects

and February 1998 four focus groups and 10 interviews were conducted.

Group brainstorming or personal interviews were used to identify potential health impacts. At these sessions, informants were given a checklist of main influences on health (table 3) and a summary of the proposed development. Health impact assessment is essentially a deductive qualitative method as informants work through the list of categories of health influences to identify potential health impacts for each project stage and assess how probable and measurable they are. Along with identifying all possible health impacts, interviewees were asked for their main priorities and encouraged to suggest recommendations.

Members of the brainstorming sessions were given the researcher's contact number, if they wished to discuss any sensitive issues regarding the development in private. Sessions were taped and transcribed. Interviews were conducted if preferred or where it was not feasible for participants to attend the brainstorming sessions. Opinions of experts on environmental and transport issues were sought via telephone interviews.

There was general agreement on what were the main priority areas. It was not part of the process of this health impact assessment to send details of the literature to key informants. This was unnecessary for two reasons. The key influences on health are derived from extensive research from a number of disciplines on what are the main determinants of health. The literature complements the views expressed by the key informants.

Analysis of interview data for each category identified all potential health impacts and the population groups they were likely to affect, supported by a review of evidence for potential health influences. Seven categories of influence were then selected, on the basis of those most frequently chosen as the main priority and therefore reflecting participants' areas of concern; where the programme was considered to have the most health impact, particularly a precursor role to several other health impacts; and where changes could be incorporated. Recommendations were made with the advice of the New Wallasey Health Impact Assessment Group to maximise positive and reduce negative health impacts for the priority areas.

\section{Results}

Areas surrounding the site of the Twelve Quays are the most deprived in New Wallasey, which have standardised mortality ratios (SMRs) higher than England and Wales. There were raised SMRs for ischaemic heart disease and lung cancer and high numbers of people with long term limiting illness. ${ }^{19}$ The area also suffers from a maximum high unemployment rate of $21 \%$ among the working age population. Seventy one per cent at age 19 have five general certificates of secondary education/national vocational qualifications level 2, but only $43 \%$ of workforce have national vocational qualifications level 3 or advanced general national vocational qualifications. ${ }^{17}$

The locality contains Pathways areas selected for economic regeneration from European Objective One funding. These Pathways areas have shared concerns over the level of drug and alcohol abuse, unemployment, fear of crime, anti-social behaviour and the need for environmental improvements. ${ }^{18-20}$

\section{PRIORITY IMPACT AREAS}

Priorities are summarised in tables 4 and 5 . Impacts from transport and civic design could be seen in either a negative or a positive light depending on how they will be handled. In view of this a negative and positive scenario was given in the main report. ${ }^{13}$

\section{TRANSPORT AND TRAFFIC}

From a negative scenario during the construction and operational stages there will be an expected increase of $50 \%$ in peak hour traffic from construction lorries, staff and visitor 
Table 4 Priority health impacts during the development stage

\begin{tabular}{|c|c|c|c|}
\hline \multirow[b]{2}{*}{ Category of influence } & \multicolumn{2}{|c|}{ Predicted health impacts (Quantifiability of impact: (Q) qualitative; (E) estimable; $(C)$ calculable) } & \multirow{2}{*}{$\begin{array}{l}\text { Certainty of impact } \\
\text { Definite }(D) ; \\
\text { Probable }(P) ; \\
\text { Speculative (S) }\end{array}$} \\
\hline & Positive & Negative & \\
\hline Education/training & Stimulate training in mathematics/science for jobs in TTL/Centre (C) & & $\mathrm{D}$ \\
\hline \multirow[t]{2}{*}{ Economic } & 1. Construction jobs $(\mathrm{C})$ & & $\mathrm{D}$ \\
\hline & 2. Attract more inward investment to area $(\mathrm{C})$ & & $\mathrm{P}$ \\
\hline Land use & Revitalise dock estate on derelict land (C) & & $\mathrm{D}$ \\
\hline \multicolumn{4}{|c|}{ the- } \\
\hline road traffic accident risk & & Increase during construction $(\mathrm{C})$ & $\mathrm{D}$ \\
\hline air and noise pollution & Pollution reduced if cleaner freight vehicles used (Q) & & S \\
\hline Transport & Stimulate development of public transport $(\mathrm{C})$ & & D \\
\hline
\end{tabular}

Table 5 Priority health impacts during the operational stage

\begin{tabular}{|c|c|c|c|}
\hline \multirow{2}{*}{$\begin{array}{l}\text { Category of } \\
\text { influence }\end{array}$} & \multicolumn{2}{|c|}{ Predicted health impacts (Quantifiability of impact: (Q) qualitative; (E) estimable; (C) calculable) } & \multirow{2}{*}{$\begin{array}{l}\text { Certainty of impact } \\
\text { Definite }(D) ; \\
\text { Probable }(P) ; \\
\text { Speculative (S) }\end{array}$} \\
\hline & Positive & Negative & \\
\hline Education & Opportunities for adult education & & \\
\hline \multirow{6}{*}{$\begin{array}{l}\text { Accident risk } \\
\text { Civic design }\end{array}$} & & More traffic travelling to site $(\mathrm{C})$ & $\mathrm{D}$ \\
\hline & Good design- & & \\
\hline & 1 Pleasing; aesthetic value, up-lifting (Q) & & $\mathrm{P}$ \\
\hline & 2 Enhance perceptions of safety $(\mathrm{Q})$ & & $\mathrm{P}$ \\
\hline & 3 Discourage criminal activity (Q) & & $\mathrm{P}$ \\
\hline & 4 Safety around walkways $(\mathrm{Q})$ & & $\mathrm{P}$ \\
\hline Disabled access & 5 Opportunity to participate for disabled (Q) & & $\mathrm{P}$ \\
\hline \multirow[t]{6}{*}{ Economic } & 1 Attracting visitors to area $(\mathrm{C})$ & & $\mathrm{D}$ \\
\hline & 2 Encourage inward investment (C) & & $\mathrm{P}$ \\
\hline & 3 Direct jobs on site $(\mathrm{C})$ & & $\mathrm{D}$ \\
\hline & 4 Indirect jobs in support industries (E) & & $\mathrm{D}$ \\
\hline & & $\begin{array}{l}5 \text { Maybe increase in car ownership through monetary } \\
\text { resources if employed (Q) }\end{array}$ & $\mathrm{P}$ \\
\hline & & $\begin{array}{l}6 \text { If not affordable will not be used by disadvantaged } \\
\text { groups (Q) }\end{array}$ & $\mathrm{P}$ \\
\hline \multirow[t]{3}{*}{ Exercise } & Encouraged & & \\
\hline & 1 Walking to site $(\mathrm{Q})$ & & $\mathrm{S}$ \\
\hline & 2 Cycling if cycleway (Q) & & $\mathrm{P}$ \\
\hline Lifestyle & $\begin{array}{l}\text { If employed at centre maybe able to afford a better lifestyle } \\
\text { (Q) }\end{array}$ & & $\mathrm{S}$ \\
\hline \multirow{3}{*}{ Pollution } & & Noise and air from traffic $(\mathrm{C})$ & $\mathrm{D}$ \\
\hline & $\begin{array}{l}\text { Petrol station on site would avoid driving into residential } \\
\text { areas (Q) }\end{array}$ & & $\mathrm{P}$ \\
\hline & $\begin{array}{l}\text { Clean high technology industry further enhanced if energy } \\
\text { efficient building }(\mathrm{C})\end{array}$ & & $\mathrm{D}$ \\
\hline \multirow[t]{2}{*}{ Public safety } & & Risk of crime, isolated location at night (Q) & $\mathrm{P}$ \\
\hline & & Risk of youths swimming in land locked water (Q) & $\mathrm{P}$ \\
\hline
\end{tabular}

transport. ${ }^{22}$ Pressure for extensive secure parking is forecast, particularly in the winter months when the use of dry, warm private family transport will be preferred. The site offers incentives to use private transport with easy access to main roads, the motorway system and the Mersey tunnels. This particular area of the docklands is currently poorly served by public transport in an isolated location. Increase in traffic volume will lead to a more hostile urban living environment for children. ${ }^{23}$ The understandable parental restrictions on their children's physical activity could exact a considerable price in terms of future health problems, ${ }^{24}$ particularly cardiovascular. ${ }^{25}$ Increasing traffic flows also heighten personal fears for safety that reduce participation in cycling and walking with a subsequent loss of health benefits from these activities. Indeed, walkers and cyclists are exposed in traffic to accidental injury, noise pollution and stress. ${ }^{25}$

Although in a remote spot from residential housing, expanded traffic will increase pollution from both air and noise while heightening the risk of road traffic accidents. A growing body of research has proved a link between transport pollution and respiratory illness and other health problems such as cancer to vulnerable people. ${ }^{26}$ Approximately $38 \%$ of a population are at risk of suffering adverse reactions from exposure to air pollution. ${ }^{26}$ Traffic noise has been associated with harmful health effects, in particular sleep disturbance, mental health problems and significant effects on concentration, stress levels, raising blood pressure, increasing likelihood of aggressive behaviour ${ }^{28}$ and health worries. ${ }^{28}$

From a positive scenario the expected increase in traffic to the site could have positive benefits by encouraging affordable, clean alternatives to private cars and road freight. This would be particularly beneficial if "environmentally friendly" vehicles were used such as trams or battery charged buses. Vehicles taking separate routes from houses could be encouraged by having a petrol station situated at or next to the Twelve Quays site. If an attractive cycleway and a walkway were developed this would encourage people to take exercise, particularly if the development was located on a pleasant landscaped site. There is a general consensus, based on a large body of research, on the benefits in health status from physical activity. The main benefit being a reduction in the risk of coronary heart disease, osteoporosis, a positive effect on psychological well being ${ }^{29} 30$ reduction in obesity and improved overall fitness. $^{31}$ 
Reducing traffic to the area would help in reducing pollution and road traffic accidents. Furthermore, it would also reduce noise and the stress of driving in heavy traffic. Public transport that enabled easy access for disabled and pram users would encourage such visitors by ensuring stress free travel.

"Where public transport provides an affordable and reliable alternative to the car, the health impact of travel on communities has been shown to be less harmful, as bus travel is one of the safest forms of travel." ${ }^{25}$ Therefore, strategies that reduce the need for car travel or substitute car travel with safer forms of transport could substantially reduce population death rates. Increasing the number of restricted $20 \mathrm{mph}$ zones would also help to reduce casualty rates, levels of pollution and improve quality of life. ${ }^{24}$

The safety of those with a disability needs to be considered as they have more accidents while travelling on public transport or walking than sighted people. Measures such as tactile surfaces to warn of steps and curbs would help to reduce accidents. According to the Wirral Metropolitan Borough Engineers, a traffic safety audit should be completed at the preliminary and detailed design stage of the International Astronomy and Space Exploration Centre and maintained once in place.

CIVIC DESIGN AND SAFETY

Civic design in this context refers to the implications of the design of the site and the centre. A negative scenario reflects on how poor design neglects any theme for the site, to enhance its aesthetic value, tourism and public safety. The proposed site is in a very isolated spot away from any established residential areas or pleasant shopping facilities, served by a lonely dock road. The proposed centre is separated from a planned roll on roll off ferry by landlocked stagnant water. On its other side, a road separates it from, what have been described as "cheap" industrial warehouses. The development will be disconnected from other developments near the waterfront by another section of landlocked water.

The spatial design, lacking no night time tourist attractions, could result in no-go public areas after sunset. These dark, dangerous, vulnerable areas and blind spots could facilitate, nefarious activities, from vandalism, gang meeting places, petty crime, burglary, drug pushing, prostitution and so forth. All this around the foul, stagnant water that has collected the waste litter from the day's visitors. A reactive response to criminal activity would be to have a fortress with barbed wire covering high walls, prominent security, guard dogs and closed circuit television cameras. The Twelve Quays could deteriorate into "a third rate industrial estate". A hotchpotch design of tourism, leisure and industrial estates has emerged elsewhere on the Wirral, creating a nightmare for night time security.

From a positive scenario, an attractive, sustainable, energy efficient, clean building could be situated on a well maintained and managed thematic site. This will enhance its working environment, public safety; a visitor's enjoyment providing an advantage point to appreciate the famous Liverpool skyline. Good design has a spiritual quality that can be very psychologically uplifting. It should have easy access for disabled people and enable them equal participation. The use of trees and mounds to camouflage areas that are not part of the tourist theme would enhance the appearance of the site for visitors. Superior lighting of the site will eliminate otherwise dark, vulnerable areas and protect against accidents while increasing the public's perceptions of and actual safety.

SECURITY AND PUBLIC SAFETY

The land was previously docklands but the inland waterways have silted up. This raised strong concerns from the local community, about the possible contamination of the land and water, which attracts the young for swimming during the summer. As the water is landlocked, there is no natural current to stop stagnation. Once the silt is disturbed, bad smells may arise. Ongoing decontamination or oxygenation through a flow of water into the waterways has been suggested as essential. The Twelve Quays is exposed to high winds and high tides. Walkways need protection from the sea and waterways and on site life saving equipment, a first aid post and qualified rescue staff.

During construction, valuable materials will need securing by sectioning off the site from public access and a night watchman employed. After the construction building debris will need to be taken away.

High technology on the site will possibly attract burglars. Centralised closed circuit television could be linked to the nearby Hamilton Quarter network. A well lit car park controlled by visible security staff will encourage people to visit. Vandalism from local youths could be reduced if there was genuine engagement and involvement of them, particularly if they could learn transferable skills. Facilities at the centre could be hired out to local community groups.

The site of the whole Twelve Quays would benefit from an environmental task force and site management team, particularly for centralised waste disposal. Childcare provision is another facility that could be organised on a shared basis, as this can be very expensive to run. Certain environmental cues are associated with fear of crime that can lead the public to avoid such places, particularly in the absence of capable others to act as guardians. ${ }^{33}$ The environmental conditions include reduced visibility from inadequate lighting ${ }^{32}$; places of concealment for an offender (trees, shrubs and walls) ${ }^{33}$; blocked escape for the passer $\mathrm{by}^{33}$; perceptions of deterioration (litter on streets, vandalism, run down buildings) and uncivil behaviour by youths. ${ }^{34}$ Criminals will use these features in the environment to reduce their risks of being caught and to increase their payoffs. ${ }^{35}$ An attractive building and well maintained environment will be aesthetically pleasing, will encourage people to visit, while reducing fear 
of crime and actual risk of crime. Certain police schemes such as "secure by design" as well as health and safety regulations attempt to reduce environmental cues. ${ }^{36}$

\section{EMPLOYMENT}

Most interviewees were concerned that every effort should be made to encourage local people to be employed during construction and the operation of the development. There would be a range of service and security work that would be available as well as employment for local science graduates. If local further education colleges were made aware of the employment opportunities, they could ensure that local people had the relevant skills and training. Part time work would also be useful for parents of young children.

It was also thought that local people might be encouraged to set up their own business for instance, centralised site cleaning and crèche facilities. The development of the Twelve Quays site would also act as a catalyst for inward economic investment from other major employees. This development of clustering activity will "help to boost the local economy and attract further investment into the area. ...Firms will benefit from being near to similar firms since this high concentration . . .will attract suppliers and skilled labour into the area. ...the costs of training [such as] the funding of courses at local colleges can be shared." ${ }^{\prime 37}$

The development would bring advanced technology work into the Merseyside region and endeavour to sub-contract to local companies to manufacture parts. Jobs in new local hotels, retail outlets on the waterfront could also be stimulated from visitors to the centre and from the roll on and roll off ferry.

Employment would greatly boost self esteem for those previously unable to secure employment. Consequential higher income enables a better lifestyle in terms of diet, exercise and more social contacts. There is substantial evidence, particularly from prospective studies of a negative relation between unemployment and psychological and physical ill health, such as significantly higher rates of psychiatric disorder, ${ }^{38}$ heart disease and mortality. ${ }^{39}$ Furthermore, unemployment is the single most important cause of poverty in the UK..$^{40}$ Poverty's strong associations to health status have been described as "one of the most pervasive and enduring observations in public health". ${ }^{41}$ "Financial hardship and economic deprivation set limits to the extent to which the unemployed person can fulfil needs and values and move towards important future goals". ${ }^{42}$

Long term unemployed have been shown to adapt overtime to their circumstances by lowering their employment commitment, which can set up a vicious circle where they are less likely to become employed. Indeed on the Wirral this problem has been reported "...with such high unemployment, people effectively withdraw from the labour force and see no point in training or retraining themselves. ${ }^{37}$
ADULT EDUCATION

Many local people felt that they would not wish to visit. "That it would appear to be only for boffins". To encourage adults, the centre could stage a number of general interest introductory courses for local people. Accredited courses could be offered that would encourage an awe of science while giving practical hands on experience. Attendance at adult evening classes would ensure that the site would be busy, which could have security and safety implications as outlined above under security and public safety.

There is a strong association between good educational achievement and employment, decent wages, good health and living in affluent areas. ${ }^{43}$ National and international evidence shows wide variations in health between social groups who have a high educational level and those who have a poor educational achievement. ${ }^{44}$ The outlook for someone with a poor educational level appears to be bleak as they are more likely to be unemployed or have a low paid job, with consequent poorer health, unhealthy lifestyles and premature mortality. ${ }^{45}$ This is not considered to be a reflection of innate ability but the uneven availability of educational opportunities to social groups. ${ }^{46}$ Education has been shown to be a good predictor of women's self assessed health. ${ }^{47}$ Knowledge and skills are prized in mature industrial societies whereas unskilled jobs in traditional industries move to emerging countries or are replaced by technology.

The participation in a learning experience has a positive psychological effect on health. Concentration and mental effort required could detract from worries and problems. The learning of a new skill would raise self esteem and confidence. A sense of time being structured in purposeful activity has been shown to have a positive impact on mental health. ${ }^{47}$ Even among unemployed people the more active they are the better their psychological health. ${ }^{48}$ Participation in a group activity would bring positive reinforcement from social interaction.

\section{Recommendations}

As far as possible, the main concerns and suggestions of the key informants have been formulated into recommendations, which are listed in table 6 . In many cases further investigations will have to be carried out before specific recommendations can be made. For instance, recommendations have not been made around issues of affordability (which was raised as an important priority) as this was investigated by a feasibility study. Furthermore, progress has already been made on the planning of adult education, so there is no necessity for further action. The adjacent pathways areas were keen that screening of vulnerable people such as asthmatic persons and others prone to respiratory illness, take place because of risks from traffic pollution. Recommendations have been made which aim to reduce air pollution arising from the development. Screening of people is not appropriate, as the population monitoring of prevalence 
Table 6 Recommendations

\begin{tabular}{|c|c|c|}
\hline Health determinant & \multicolumn{2}{|c|}{ Recommendation } \\
\hline Transport and traffic & $\bullet$ & $\begin{array}{l}\text { Ensure that good quality public transport is available to the Twelve Quays from both } \\
\text { Birkenhead and Wallasey. When planning permission is being sought, it is } \\
\text { recommended that environmental and traffic impact assessments bear in mind the } \\
\text { proposals in this health inpact assessment. They should take into consideration } \\
\text { measures to reduce and monitor accidents, air and noise pollution. } \\
\text { Heavy goods vehicles should use routes away from residential areas. This would be } \\
\text { encouraged by having a petrol station situated at or next to the Twelve Quays site so } \\
\text { lorries and tourist traffic would not need to go into residential areas for fuel. } \\
\text { Encourage exercise through walking and cycling by the investment of clearly signed, } \\
\text { safe and attractive routes to the site. } \\
\text { Continue to monitor asthma prevalence rates and hospital admissions with asthma. }\end{array}$ \\
\hline Civic design & $\bullet$ & $\begin{array}{l}\text { Local children could make suggestions as to what they would like to see at the centre. } \\
\text { Senior design students could design a particular area (such as a crèche) if it was } \\
\text { considered feasible. } \\
\text { As far as possible, building design should take into consideration sustainable } \\
\text { development through the prudent use of natural resources in an energy efficient } \\
\text { building. } \\
\text { An expert access audit on development plans should be commissioned. The audit will } \\
\text { take into consideration the varied needs of people with different disabilities. This will } \\
\text { save money in the long run from having expensive alterations completed later and will } \\
\text { ensure that the disabled will not be discriminated against in employment or } \\
\text { participation. Detailed cost of implementing the recommendations is outside the scope } \\
\text { of this study. Advice and information from quantity surveyors and suppliers of } \\
\text { specialist equipment would have to be sought. }\end{array}$ \\
\hline Security and public safety & $\bullet$ & $\begin{array}{l}\text { As far as possible local people, particularly the young, should be involved in the design } \\
\text { of publicity. "Ownership" of the development will not only encourage participation, } \\
\text { but may also protect against vandalism from a small minority who may feel excluded. } \\
\text { Dangerous areas, which might be vulnerable to criminal activity and accidents, should } \\
\text { be eliminated. Community safety advice should be sought by the developers of the site } \\
\text { from the Health and Safety Executive and the police architectural liaison officer. } \\
\text { A traffic safety audit should be completed at the preliminary and detailed design stage } \\
\text { of the development and maintained once in place. }\end{array}$ \\
\hline Employment and training & $\bullet$ & $\begin{array}{l}\text { The feasibility study should investigate the provision of affordable access to local } \\
\text { people, particularly the unemployed and others on a low income. } \\
\text { The centre should work closely with the training agencies so that local people will have } \\
\text { the right skills for employment and enable them to use their skills in publicity. }\end{array}$ \\
\hline
\end{tabular}

rates of asthma and admissions to hospital is already carried out and should continue.

The Docklands programme steering group received and discussed the report. They recommended that it should be made available to all developers on the site. Prospective developers on the site have been given a copy of the executive summary of the full health impact assessment, so they can be alerted to potential health impacts and conform to relevant recommendations in their plans. The implementation of the recommendations will be overseen by the New Wallasey Single Regeneration Budget Dockland Programme Steering Group and will be included in appropriate action plans.

\section{Discussion}

This study has been one of the first to use these methods of health impact assessment. They are based on a holistic definition of health where quality of life can be influenced by many factors including employment, education, housing, pollution, safety and inequality of access to services. Substantial evidence suggests that these broad key areas of influence can have an impact on a population's health. However, health impacts cannot always be measured in quantifiable terms to make accurate predictions for instance numbers of asthma sufferers, new cases of cancer, episodes of mental illness and so forth, which is beyond the scope of these methods, as too is a cost-benefit analysis. The main aim of this study was to pilot the methods for health impact assessment not to look at issues of opportunity cost. In a health impact assessment that involves a regeneration project that strives to improve the quality of life of local communities it is impossible to meaningfully quantify outcomes as they are of a qualitative nature. There will also be cumulative effects from this project and adjacent developments. Developing a quantitative model of health impact assessment for environmental factors is very complex and only in its early stages (McCarthy M, 3rd UK health impact assessment conference, Liverpool, 2000).

Bias can also influence a health impact assessment, as it is necessary to consult experts that may have a vested interest in the success of a policy, project or development. They can make claims for health gains that are difficult to substantiate or disprove through lack of evidence. To support a potential health gain it is difficult to draw conclusions from studies that have been carried out on different populations in other contexts. The specific social fabric of one society may enhance the effectiveness of development projects, but these same projects may not be effective in a different social milieu or political context.

Health impact assessment may also be found wanting by qualitative researchers who prefer to use a more inductive approach, which are not based on a priori categories (see table 1). These categories cover a very broad spectrum of influence, which by necessity make the health impact assessment lack in depth analysis into a specific area of influence, which is the hallmark of qualitative techniques.

Health impact assessment methods are in their infancy, and have not been widely used in the UK, but they offer the means of engaging those directly affected by developments in a 
KEY POINTS

- Health impact assessment is a structured method to enable key stakeholders to predict health influences during the planning of a development.

- Recommendations are made to maximise potential positive health while minimising any negative health consequences.

- This paper gives an example of a recent health impact assessment of a proposed regeneration development.

constructive way early in the planning process. The stages of this process are participatory, requiring input from many individuals involved with the development. In addition to "experts", these include representatives of public and voluntary sectors and of local communities whose evidence helps identify health impacts and suggest management strategies to maximise health gains.

Health impact assessment's major strength is as a method of involvement, as local people were able to contribute their specific local knowledge and understanding alongside experts in specific fields. It allows the various views of all stakeholders to be considered equally. Furthermore, it enables community concerns to surface and be resolved and avoids them becoming major obstacles later in the planning process.

The participatory process has enabled people to have an opportunity to be consulted about regeneration work in their locality. Therefore, there has been considerable progress on priority concerns. Merseytravel is considering a range of phased improvements to public transport links. There was concern about the quality of the land and water around the site, but no evidence has been found of any contamination. In view of the priority given to provision of adult education and the centre's determination to facilitate an understanding of science, proposals for adult education are being considered. In recognition of the need to improve local skill levels and science facilities, a bid was sent to the former Government Office for Merseyside for the European Regional Development Fund. Discussions will be taking place with the International Astronomy and Space Exploration Centre to establish what skill levels will be required for future employees.

Methodological issues remaining to be resolved include the representativeness of key informants. It is likely that as methods develop, this will be tackled in a systematic way. Monitoring and evaluation of health impact assessments is still in its infancy: an agreed approach is also a methodological priority. Additional issues for future development include strengthening the evidence base and creating systematic databases of relevant evidence for use in health impact assessment.

The author wishes to thank Dr Alex Scott-Samuel for reading through draft manuscripts and providing useful feedback.

Funding: Wirral Health.

Conflicts of interest: none.
1 Scott-Samuel A. Health impact assessment-theory into practice. 7 Epidemiol Community Health 1998;52:704-5.

2 World Health Organisation. WHO constitution final Acts. International Health Conference. New York: World Health Organisation, 1946.

3 Ashton J. The health of the North West of England. Report of the Regional Director of Public Health 1995. Warrington: North West Regional Health Authority, 1996.

4 Milio N. Making healthy public policy; developing the science by learning the art: an ecological framework for policy studies. Health Promotion 1998;2:263-73.

5 Draper P. Health through public policy: the greening of public health. London: Green Print, 1991.

6 Drever F, Whitehead M, eds. Health inequalities. London: Office for National Statistics, 1997.

7 Acheson D. Independent inquiry into inequalities in health. London: The Stationery Office, 1998.

8 Department of Health. The new NHS, modern, dependable. London: The Stationery Office, 1997.

9 Department of Health Our healthier nation: a contract for health. London: The Stationery Office, 1998

10 Fleeman N. Health impact assessment of the Southport drug prevention initiative. Observatory Report Series no 39.1
Liverpool: Liverpool Public Health Observatory, 1997.

11 Fleeman N. Prospective health impact assessment of the Merseyside integrated transport system (MERITS). Observatory Report Series no 45. Liverpool: Liverpool Public Health Observatory, 1999.

12 Winters L, Scott-Samuel A. Health impact assessment of the community safety projects - Huyton SRB area. Observatory Report Series no 38. Liverpool: Liverpool Public Health Observatory, 1997.

13 Winters L. Health impact assessment of the international astronomy and space exploration centre. Twelve Quays, Wirral. Observatory Report Series no 43. Liverpool: Liverpool Public Health Observatory, 1998.

14 Scott-Samuel A, Birley M, Ardern K. The Merseyside guidelines for health impact assessment. Liverpool: Merseyside health impact assessment steering group/Liverpool Public Health Observatory, 1998 .

15 Population Health Resource Branch. Health impact assessment toolkit. British Columbia: Ministry of Health, 1994.

16 Ewan C, Young A, Bryant E, et al. National framework for environmental and health impact assessment. National Health and Medical Research Council. Canberra: Australian Government Publishing Service, 1994.

17 Wirral Partnership. New Wallasey delivery plan 1997/98. Birkenhead: Wirral Partnership, 1997.

18 Pathways Wirral. Action plan for partnership area: Seacombe and Poulton. Birkenhead: Pathways Support Unit, Metropolitan Borough of Wirral, 1997.

19 Pathways Wirral. Action plan for partnership area: Birkenhead. Birkenhead: Pathways Support Unit, Metropolitan Borough of Wirral, 1997.

20 Pathways Wirral. Action plan for partnership area: Egremont. Birkenhead: Pathways Support Unit, Metropolitan BorBirkenhead: Pathways
ough of Wirral, 1997.

21 Wirral Health Information and Public Health Departments. Preliminary locality profile: Wallasey. Birkenhead: Wirral Health, 1996.

22 JMP Consultants Ltd. Traffic impact study. London: JMP Consultants Ltd, 1995.

23 Roberts I. Why have child pedestrian death rates fallen. BMF 1993;306:1737-9.

24 BMA Science Department. Road transport and health, London: British Medical Association, 1997.

25 Royal Commission on Environmental Pollution. Transport and the environment. London: HMSO, 1994.

26 British Lung Foundation. Transport and pollution -the health British Lung Foundation. Transport and pollution
costs. London: British Lung Foundation, 1998.

27 Institute of Environmental Health Officers. Transportation: the route to health report. London: Institute of Environmental Health officers, 1993

28 Lercher P, Kofler W. Behavioural and health responses associated with road traffic noise exposure along alpin through-traffic routes. Sci Total Environ 1996;190:85-9.

29 Glenister D. Exercise and mental health - a review. F $R$ Soc Health 1996;116:7-13.

30 Byrne A, Byrne DG. The effect of exercise on depression, anxiety and other mood states - a review. 7 Psychosom Research 1993;37:565-74.

31 British Medical Association. Cycling: towards health and safety. Oxford: Oxford University Press, 1992.

32 Painter $\mathrm{K}$. The influence of street lighting improvements on crime, fear and pedestrian street use, after dark. Landscape and Urban Planning 1996;35:193-201.

33 Nasar JL, Fisher B. Design for vulnerability - cues and reactions to fear of crime. Sociology and Social Research 1992;76:48-58

34 Miethe TD. Fear and withdrawal from urban life. The Annals of the American Academy of Political and Social Science 1995;539:14-19.

35 DeFrances CJ, Titus RM. Urban planning and residential burglary outcomes. Landscape and Urban Planning 1993;26: 179-91

36 Ekblom P. Less crime by design. The Annals of the American Academy of Political and Social Science 1995;539:114-29.

37 CEWTEC. Economic assessment for 1998-99: local authority district report Wirral. Birkenhead: Chester Ellesmere Port Wirral Training Enterprise Council, 1998.

38 Fergusson DM, Horwood LJ, Lynskey MT. The effects of unemployment on psychiatric illness during young adulthood. Psychol Med 1997;27:371-81. 
39 Cook DG, Barkey MJ, Cummins RA, et al. Health of unemployed middle-aged men in Great Britain. Lancet 1982;1: ployed mid.

40 Dean M. Unemployment and health. Lancet 1993;341:230-1.

41 Kaplan GA, Pamuk ER, Lynch JW, et al. Inequality in income and mortality in the United tality and potential pathways. BMF 1996;312:999-1003.

42 Feather NT. Economic deprivation and the psychologica impact of unemployment. Australian Psychologist 1997;32 impact 45 .

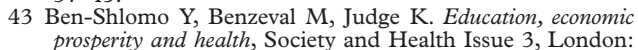
King's Fund Policy Institute, 1996.
44 Benzeval M, Judge K, Whitehead M, eds. Tackling inequalities in health: an agenda for action. London: King's Fund, 1995.

45 Dahl E. Social inequality and health. The role of the healthy worker effect. Soc Sci Med 1993;36:1077-88.

46 Arber S. Comparing inequalities in women's and men's health: Britain in the 1990s. Soc Sci Med 1997;44:773-87.

47 Wanberg CR, Giffiths RF, Gavin MB. Time structure and unemployment: a longitudinal investigation. Fournal of Occupational and Organizational Psychology 1997;70:75-95.

48 Underlid KNA. Activity during unemployment and mental health. Scand F Psychol 1996;37:269-81. 